\title{
anemon
}

Muş Alparslan Üniversitesi Sosyal Bilimler Dergisi

Journal of Social Sciences of Muş Alparslan University

Yı//Year: 2016 • Cilt/Volume: 4 • Sayı/Number: 2

ISSN: 2147-7655 • e-ISSN: 2149-4622

ÖZGÜN ARAŞTIRMA • ORIGINAL ARTICLE

\section{Sağlık Personeli Hasta Güvenliği Kültürü Algılarının Değerlendirilmesine Yönelik Bir Araştırma}

\author{
Fuat KORKMAZER ${ }^{1, \mathrm{a}}$, Ahmet YILDIZ $^{2}$, Erhan EKINGGEN ${ }^{3}$
}

${ }^{1}$ Öğr. Gör., Muş Alparslan Üniversitesi, Sağlık Yüksekokulu, Muş/ Türkiye

${ }^{2}$ Arş. Gör., Dicle Üniversitesi, İiBF, Sağlık Yönetimi Bölümü, Diyarbakır/ Türkiye

${ }^{3}$ Öğr. Gör., Batman Üniversitesi, Sağlık Hizmetleri Meslek Yüksekokulu, Batman/ Türkiye

Başvuru tarihi: 01 Haziran 2016 Düzeltme tarihi: 07 Eylül 2016 Kabul tarihi: 27 Eylül 2016

Öz

Dünyadaki bütün sağlık bakım sistemleri, yardım almak için kendilerine başvuran hastalara ara sıra istemeden zarar vermektedir. Güvenlik programına dayalı uygulama yapan sağlık kurumlarında, güvenlik kültürünün geliștiği ve hastalara verilen zararın azaldığı görülmektedir. Sağlı kurumlarında hasta güvenliğini artırmak için öncelikle hasta güvenliği kültürünün oluşturulması gerekmektedir. Hasta güvenliğini sürdürmeyi destekleyen personel algıları, önemli bir ölçüm olarak ortaya çıkmaktadır. Bu çalışmada, bir kamu hastanesinde çalışan 76 sağlık personelinin hasta güvenliği algılarının sosyo-demografik özelliklere göre değerlendirilmesi amaçlanmıştır. Veri toplama aracı olarak sağlık personeli için Hasta Güvenliği Kültürü Hastane Anketi kullanılmıştır. Araştırmada, sağlık personeli hasta güvenliği algılarının meslekte çalışma süresine ve çalıştığı birime göre farklılık gösterdiği, sağlık personelinin \% 67,1'inin son bir yıl içerisinde hiçbir olay raporu doldurmadığ görülmüştür.

\section{Anahtar Kelimeler}

Hasta Güvenliği, Hasta Güvenliği Kültürü, Personel Algıları

\footnotetext{
a Sorumlu Yazar/Correspoding Author: Muş Alparslan Üniversitesi Kampüsü, Sağlık Yüksekokulu, Sağlık Yönetimi Bölümü, Diyarbakır Yolu 7. Km, 49250, Muş / Türkiye. e-posta: f.korkmazer@alparslan.edu.tr 


\title{
An Application for Assessing Patient Safety Culture Perceptions of Health Personnel
}

\begin{abstract}
All health care systems in the world occasionally give harm to patients who apply to them unintentionally. In healthcare institutions performing applications based on security software, it has been seen that the safety culture has improved and the harm given to the patients has declined. In order to improve patient safety in health care settings, we need to establish a culture of patient safety. Personnel perceptions supporting patient safety emerges as an important measurement. The aim of this research is to evaluate the perception of 76 health personnel on patients' safety culture according to the sociodemographic features. As data collection tool for health care providers, Hospital Survey on Patient Safety Culture was used. In the study, it has been seen that the health personnels' perceptions about patient safety differ according to working years and working units. It has been seen that $\% 67,1$ of health personnel didn't fill in any event report and that the average point of the hospital's patient safety is 2,68 .
\end{abstract}

Keywords

Patient Safety, Patient Safety Culture, Perception of Personnel

\section{GİRIŞ}

Bir kurumun genel kültürünün özellikli bir yönü olan hasta güveliği kültürü, hasta güvenliğine odaklanan sağlık kurumlarında bir öncelik haline gelmekte ve gittikçe artan bir ilgi görmektedir (Sorra ve Dyer, 2010: 1). Sağlık hizmeti sunumunun her aşamasında, tıbbi hataların önlenmesi ve hasta güvenliğinin sağlanması, sağlık sisteminin öncelikleri arasındadır (Güven, 2007: 411).

Sağlık bakım hizmetleri, özellikle ciddi hastalıkları tedavi etmek için hastanede sunulan karmaşık hizmetler "yüksek riskli endüstri”" grubuna girmektedir. Bu endüstriler öldürme ya da sakat bırakma gücü olan faaliyetleri içermektedir. Dünyadaki bütün sağlık bakım sistemleri, sağlık hizmeti almak için kendilerine başvuran hastalara bazen istemeden zarar verebilmektedir (Kaya, 2009: 32).

Önlenebilir olumsuz olaylar (tıbbi hatalar) Amerika Birleşik Devletleri'nde (ABD) ölümün temel bir nedenidir. 1997 yılında ABD hastanelerine 33,6 milyonun üzerinde hastanın kabul edildiği düşünülürse 44.000-98.000 arasında hastanın her yıl tıbbi hatalar sonucunda öldüğü tahmin edilmektedir. Toplam ulusal maliyetlerin olumsuz olaylar için (gelir kaybı, hane halkı üretim kaybı, maluliyet, sağlık hizmeti maliyetleri) 37,6 - 50 milyar dolar ve önlenebilir olumsuz olaylar için 17 - 29 milyar dolar arasında olduğu tahmin edilmektedir. Daha düşük tahminler kullanılsa bile, 1996'da toplam maliyetleri oluşturan olumsuz olaylar ve önlenebilir olumsuz olaylar toplam sağlık harcamalarının sirasıyla \% 4'üne ve \% 2'sine eşittir (Kohn vd., 2000: 1-2). 
$\mathrm{Bu}$ ve benzeri çok sayıdaki veri, sağlık çalışanlarının, hastaların, hasta yakınlarının, basının ve sonuçta kamuoyunun, yöneticilerin ve politikacıların dikkatinden kaçamayacak kadar önemli ve büyüktür. İngiltere'de hastaneye yatan hastaların \%10'undan fazlasında (bir yılda yaklaşık 850.000 hastada) istenmeyen olay görüldüğü, Avustralya'da hastaneye yatan hastalar arasında istenmeyen olay hızının \%16,6 olduğu ortaya çıkmıştır (Çakmakçı, 2014).

ABD'deki Ulusal Hasta Güvenliği Kurumu (The National Patient Safety Foundation) hasta güvenliğini, sağlık bakım sürecindeki olumsuz sonuçların veya zararlı engellerin iyileşmesi, önlenmesi ya da bunlardan sakınma olarak tanımlamaktadır (Institute of Medicine, 2000: 57). Naveh vd. (2005) hasta güvenliğini "tedavi hatalarının olmaması, sağlık hizmeti sunumundan kaynaklanan yaralanma ve istenmeyen olaylardan sakınılması ve istenmeyen olayların önlenmesi" şeklinde tanımlamaktadır (Aktaran: Tak, 2010: 76).

Kurumsal kültür, tüm organizasyonu bir arada tutan tutkal, kompleks değerler manzumesidir. Hasta güvenliği kültürü de, hasta güvenliğinin kurumun en öncelikli konusu ve ortak değeri olarak kabullenilmesidir (Akalın, 2004: 12-13). Hasta güvenliği kültürü, örgüt kültürünün bir parçasıdır ve hasta güvenliği ile ilgili olarak çalışanların paylaştığı tutumlar, inançlar, algılar ve değerlerden meydana gelmektedir. Sağlık kurumlarında hasta güvenliğini artırmak için hasta güvenliği kültürünün oluşturulması gerektiği yaygın bir kabul görmektedir (Kaya, 2009: 32).

\section{HASTA GÜVENLİĞi}

Hasta güvenliği, Sağlık hizmetine bağlı hataların önlenmesi ve sağlık hizmetine bağlı hataların neden olduğu hasta hasarlarının eliminasyonu veya azaltılmasıdır (Akalın, 2014: $64)$.

Hasta güvenliği ve tıbbi uygulama hatalarının toplumda algılanması ile ilgili çalışmalar özellikle konuya önem veren ülkelerde sıklıkla yapılmakta ve yıllar süresince algılamada bir değişiklik olup olmadığı değerlendirilmektedir (Altındiş, 2014: 70).

Ülkemizde 2008 yılında yapılan bir çalışmada araştırma kapsamına alınan ebe ve hemşirelerin, \%74,6'sı hasta güvenliğini "sağlık hizmetlerinin kişilere vereceği zararı önlemek amacıyla alınan önlemlerin tamamı" olarak nitelendirmiş ve hasta güvenliği uygulamalarının gerekli $(\% 96,9)$ olduğunu ifade etmişlerdir. Katılımcılar hasta güvenliği uygulamalarındaki rollerini, \%66,9 oranıyla hasta güvenliğine ait riskleri belirleyen, önlemeye yönelik uygulamalarını planlayan, uygulayan ve değerlendiren sağlık profesyoneli olarak belirtmişlerdir. Hemşirelerin hastanelerinde gerçekleştirilen hasta güvenliği uygulamalarını değerlendirmek için verdikleri puanların dağılımına baktığımızda \%72,3 oranıyla uygulamaların etkinliğini “iyi" olarak nitelendirmişler ve uygulamalara ait memnuniyetlerini ifade etmişlerdir. Ülkemizde yapılan diğer bir çalışmada, hemşirelerin \%100'ü hasta güvenliğini ilgilendiren uygulamalara önemli katkılar sağlayabileceğini, \%87,5'i hemşirelerin hataları eğitim ile önleyebileceğini; \%64,4'ü kurumda hata oluştuğunda çözüm için sorunun anlaşılmaya çalışıldığını ve tıbbi hata sonrasında \%14,4'ü ise cezalandırma/ suçlama davranışı gösterildiğini bildirmiştir (Altındiş, 2014: 70). 


\subsection{Hasta Güvenliği Kültürü}

Hasta güvenliği kültürü, örgüt kültürünün bir parçasıdır ve örgütteki bireylerin tutumları, inançları, algıları ve değerlerinden oluşur (Kaya, 2009: 32-34). Hastanelerde, hasta güvenlik kültürünün oluşturulmasında sadece kurum çalışanları ve yöneticileri değil, hastaların da hasta güvenliği konusunda bilinçlendirilmesi gerekir (Akalın, 2004: 13).

Hasta güvenliği, sağlık hizmetine bağlı hataların önlenmesi ve bu hataların neden olduğu yaralanma ve ölümlerin ortadan kaldırılmasına yönelik çalışmalardır (Akalın, 2010: 10). Ulusal Hasta Güvenliği Ajansına (National Patient Safety Agency) göre, hasta güvenliği, hastanelerde risk değerlendirme, hasta ile ilişkili risklerin yönetimi ve tanımlanması, yinelenen risklerin azaltılması için raporlanması ve analizi, geliştirilen çözümlerin uygulanması sonucu hastaya daha güvenli bakım verme sürecidir (Gözlü ve Kaya, 2012: 175).

Hasta güvenliği kültürü yaratmada olması gereken planlamanın ana hatları şöyledir (Altındiş, 2014: 71):

(i) Açık ve hatalardan ders alınabilen bir hasta güvenliği kültürü yaratılmasına çalışılmalıdır.

(ii) Hasta güvenliğinin kurumun liderleri için en önemli öncelik olduğunun ve bu amaçla takım çalışmasının en üst düzeye çıkarıldığının gösterilmesi sağlanmalıdır.

(iii) Klinik uygulamalar, işlemler, süreçler ve çalışma koşullarının devamlı değerlendirilmesi gerekmektedir. Bu çalışma ile risk yönetimi elden ele götürülmelidir.

(iv) Hasta güvenliği raporları ve seyri düzenli olarak duyurulmalıdır. Bildirim ve güvenliği arttırıcı karar-verme mekanizmalarının geliştirilmesi ve kullanılması teşvik edilmelidir.

(v) Hasta ve hasta yakınları kendi güvenliklerini korumaları ve geri bildirimde bulunmaları için özendirilmeli ve eğitilmelidirler.

(vi) Ortaya çıkan olumsuzluklar sistematik olarak değerlendirilmeli, sürekli öğrenme ve sistemlerin iyileştirilmesi konusunda rehber alınmalıdır.

(vii) Alınacak önlemlerin hatırlamaya dayalı ve cezalandırıcı olmamasına özen gösterilmelidir.

\subsection{Hasta Güvenliği Kültürü Ölçümünün Faydaları}

Sağlık hizmet sunucuları, çeşitli nedenlerle güvenlik kültürünü değerlendirmek isteyebilir. Kültürel değerlendirme şu amaçlarla kullanılabilir (Budak 2008: 55):

(i) İyileştirme yapılacak alanları belirlemek,

(ii) Hasta güvenliği hakkındaki farkındalığı artırmak için güvenlik kültürünü teşhis etmek,

(iii) Hasta güvenliği müdahalelerini ya da programlarını değerlendirmek ve zaman içindeki değişimi izlemek,

(iv) İçsel ve dışsal kıyaslama (benchmarking) yapmak,

(v) İstekleri ya da düzenleme ile ilgili gereklilikleri yerine getirmek. 
Kaliteli bir sağlık hizmeti sunmak, en önemlisi hastalara zarar vermemek için hasta güvenliği çalışmaları artırılmalı ve kültür geliştirilmelidir. Kültürün yayılması içinse gerek devlet gerekse özel kurumlar üzerlerine düşen görevleri yerine getirmeli, hasta güvenliği konusunda konuşulabilecek platformlar oluşturulmalı ve ülkenin (hastaların ve çalışanların) bu konudaki bilinci artırılmalıdır.

Bunlara ek olarak "Institute of Medicine"1n 2003 yllındaki raporunda sağlık hizmetinde kalite açısından öncelikli seçilen 20 alandan üçü hasta güvenliği ile ilgilidir. Bu alanlar medikasyon (ilaç) yönetimi, hastane infeksiyonları ve yaşlı sağlığıdır. Buradan da anlaşılacağı gibi hasta güvenliği sağlık hizmetlerinde iyileştirilmesi gereken konuların başında gelmektedir (Institute of Medicine, 2003).

Hasta güvenliğinde istenen iyileştirmelerin, sağlık hizmetlerinde kültür değişimini gerektirdiği yaygın bir şekilde kabul görmektedir. ABD'de Agency for Healthcare Research and Quality'nin (AHRQ) desteklediği hasta güvenliği projelerinin bulgularına dayanarak, hastanelerde hasta güvenliği için geliştirdiği 10 öneriden birincisi "hasta güvenliği kültürünün değerlendirilmesi ve geliştirilmesidir”. Birleşik Krallık’ta National Patient Safety Agency'nin hasta güvenliğini iyileştirmek için 7 adımlı rehberinin birinci adımı "hasta güvenliği kültürünün oluşturulmasıdır". Kanada'da Canadian on Health Services Accreditation'ın 6 hasta güvenliği hedefinden birincisi kültürdür (Kaya, 2007: 13).

Hasta güvenliğini destekleyen bir kültürün nasıl oluşturulacağı büyük merak uyandıran bir sorudur. Kliniklerde güvenlik kültürü ölçüm yollarını geliştirmek için yapılan çalışmalar artarak devam etmektedir. Hasta güvenliğini sürdürmeyi destekleyen çalışan algıları, önemli bir ölçüm olarak ortaya çıkmaktadır. Güvenlik programına dayalı uygulama yapan sağlık kurumlarının çoğunda, güvenlik kültürünün geliştiği ve hastalara verilen zararın azaldığı görülmektedir (Deilkas ve Hofoss, 2008: 1).

Hasta güvenliğini iyileştirebilmek için hasta güvenliği kültürünün geliştirilmesi gereklidir. Hasta güvenliği kültürü, hasta güvenliğinin kurumun en öncelikli konusu ve ortak değeri olarak kabullenilmesidir. Hasta güvenliği kültürü, kurumsal kültürün tüm organizasyonu bir arada tutan tutkalın, karmaşık değerler manzumesinin en önemli yapı taşı olmalıdır. Bunu sağlayabilmek için bazı çalışmaların yapılması ve uygulanması gerekmektedir. Bu çalışmaların en önemlileri şunlardır (Altındiş, 2014: 70-71):

(i) Hasta güvenliği konusunun herkesin sahiplenmesi gereken bir konu olduğunun ilan edilmesi,

(ii) Hasta güvenliği konusunda liderler, çalışanlar ve hastalar arasında açık iletişimin teşvik edilmesi,

(iii) Çalışanlara hasta güvenliğini tehdit eden işlemleri belirleme ve azaltma konusunda sorumluluk devri,

(iv) Hasta güvenliği için kaynak ayrılması,

(v) Tüm çalışanların hasta güvenliği konusunda sürekli eğitiminin sağlanmasıdır. 


\section{TIBBİ HATA}

Sağlık hizmetine bağlı hata (tıbbi hata), hastaya sunulan sağlık hizmeti sırasında bir aksamanın neden olduğu, kasıtsız, beklenilmeyen sonuçlardır. Tıbbi hatalar da kök nedenlerine göre üçe ayrılırlar (Akalın, 2014: 64):

(i) İşleme bağlı hatalar: Yanlış işlemi yapma (errors of commission: doing the wrong thing),

(ii) İhmale bağlı hatalar: Doğru işlemi yapmama (errors of omission: not doing the right thing),

(iii) Uygulamaya bağlı hatalar: Doğru işlemi yanlış uygulama (errors of execution: doing the right thing incorrectly).

(iv) Tibbi hataların maliyetinin 37.6 milyar ile 50 milyar dolar arasında olabileceği tahmin edilmektedir. Önlenebilir hataların maliyeti ise 17-29 milyar dolar arasındadir.

Tıbbi hatalar sağlık hizmetinin her evresinde ortaya çıkabilir. Bu hatalar şu başlıklar altında gruplandırılmıştır (Altındiş, 2014: 68):

(i) Medikasyon hataları (ilaç hatası): Bu hataların çoğu önlenebilir olup verilen ilaçların hastaya uygulanması süreci ile ilgilidirler. Yanlış doz, yanlış uygulama şekli, birlikte verilen başka ilaçlarla olumsuz etkileşim, alerji öyküsü sorgulamadan atopik bünyeli hastaya alerjen ilacın verilmesi, görünüşü okunuşu benzer ilaçlar gibi hatalar bu gruptadırlar. Bunların da yaklaşık yarısı önlenebilir hatalardır.

(ii) Cerrahi hatalar: Cerrahi hatalar ortalama her 50 hastada bir oluşabilmekte, ölümle bile sonuçlanabilmektedir. Yanlış taraf kesisi, beklenmedik ameliyat komplikasyonu, anestezi komplikasyonları, cerrahi enfeksiyonlar vb.

(iii) Tanı koymada hatalar: Yanlış tanı, laboratuvar testlerinin yanlış yapılması, uygulanması veya yorumlanması sık rastlanılan tıbbi hatalar arasındadır. Tanısal hatalarda eğitimsiz / deneyimsiz / denetimsiz teknisyen faktörü oldukça önemlidir.

(iv) Sistem yetersizliklerine bağlı hatalar: Sağlık hizmeti sunuş biçimi ve sistem ile ilgili aksaklıklardan kaynaklanan hatalar saptanması zor hatalardır. Bunlar arasında kullanılan aletlerdeki bozukluklar (defibrilatör, ventilatör, intravenöz sıvı pompaları vb.) ancak ortaya çıkınca saptanabilmekte, fakat çok önemli sonuçlar doğurabilmektedir. Tibbi müdahalelerde / uygulamalarda da ortaya çıkan hataların büyük çoğunluğu sistem hataları olarak tanımlanmaktadır.

(v) Diğer: Sağlık hizmeti ilintili enfeksiyonlar, kan transfüzyon komplikasyonları, sedyeden düşmeler, sıra beklemeye bağlı ölümler, Hatalı gaz / gaz karışımı verilmesi, tecavüz, hastanede intihar, yatak yaraları, hastanın kaçması, bebeğin yanlış aileye verilmesi, tehlikeli kısaltmalar vb. gibi benzeri konular da tıbbi hatalar arasında yer almaktadir. 


\section{YÖNTEM}

\subsection{Araştırmanın Amacı}

Bu çalışmada, Muş Devlet Hastanesi'nde çalışan sağlık personelinin hasta güvenliği kültürü algısının sosyo- demografik özelliklere göre değerlendirilmesi amaçlanmıştır.

\subsection{Evren ve Örneklem}

Araştırmanın çalışma evrenini Muş Devlet Hastanesi'nde çalışan sağlık personeli oluşturmaktadır. Araştırmada veri toplamak için hastane yönetiminden gerekli izin alınmıştır. Araştırma kapsamında Muş Devlet Hastanesi içerisinde yer alan 7 dahili birim (nöroloji, dahiliye, çocuk, kardiyoloji, enfeksiyon hastalıkları, gögüs hastalıkları ve cildiye), 5 cerrahi birim (beyin cerrahi, genel cerrahi, kalp-damar cerrahi, kulak-burunboğaz ve ortopedi), röntgen ve laboratuvar biriminde çalışan toplam 136 sağlık personeli bulunmaktadır. Araştırma kapsamında sağlık personeline dağıtılan anket sayısı 120, dönen anket sayısı ise 76 olup sağlık personeli için örneklemin \% 63,3'üne ulaşılmıştır.

\subsection{Veri Toplama Arac1}

Araştırmada veri toplama aracı olarak Hasta Güvenliği Kültürü Hastane Anketi (Hospital Survey on Patient Safety Culture) uygulanmıştır. Sağlık personeli için uygulanan Hasta Güvenliği Kültürü Hastane Anketi (Hospital Survey on Patient Safety Culture (HSPSC)) 2004 yılında ABD'de Agency for Healthcare Research and Quality (AHRQ) tarafindan geliştirilmiştir. Anketin Türkçe'ye çevrilmesi ve uyarlanması çalışmaları Teleş (2011), Bodur ve Filiz (2009)'in çevirisi ile birlikte Çakır (2007) ve Saraç (2009)'ın çalışmalarında kullandıkları çevirilerden de yararlanılarak yapılmıştır.

Hasta Güvenliği Kültürü Hastane Anketi 12 boyutludur ve 42 sorudan oluşmaktadır. Ayrıca katılımcılara hasta güvenliği derecesi ve raporlanan olay sayısı ile ilgili birer soru sorulmaktadır. Kişisel bilgiler bölümünde katılımcıların sosyo-demografik bilgilerini içeren 8 soru bulunmaktadır. Son bölümde ise katılımcıların yorumlarını yazmaları istenmiştir.

Anketin A, B, C, D, E, F bölümlerinde ölçeklendirme yöntemi olarak eşit aralıklı 5'li Likert tipi ölçek kullanılmıştır. G bölümünde raporlanan olay sayısı "0 olay raporu, 1-2, 3-5, 6-10, 11-20, 21 ya da daha fazla olay raporu" şeklinde 6 seçenek ile değerlendirilmiştir. Katılımcılardan "3 ve üzeri” olay raporu dolduranların sayısı çok az olduğundan, katılımcıların cevapları sadece " 0 olay raporu, 1-2 olay raporu, 3 ve üzeri olay raporu" şeklinde 3 seçenek ile değerlendirilmiştir.

Anketler toplandıktan sonra elde edilen veriler araştırmacılar tarafından SPSS 20.0 veri tabanına aktarılmış ve aktarıldıktan sonra SPSS 20.0 programında gerekli istatistiksel analizlerle değerlendirilmiştir. Sağlık personelinin hasta güvenliği kültürü algılarının değerlendirilmesinde tanımlayıcı istatistikler (ortalama, frekans, standart sapma), Kruskal Wallis Testi, Mann Whitney U Testi ve Ki-Kare Testi kullanılmıştır. Anketin güvenirliği iç tutarlılık katsayılarına bakılarak her bir faktör için ayrı ayrı hesaplanmıştır. Anketin 
güvenilirliğini test etmek için kullanılan Cronbach $\alpha$ güvenilirlik katsayısının 0,60-0,79 arasında olması anketin oldukça güvenilir olduğu şeklinde değerlendirilmektedir (Alpar, 2010:78). İncelenen faktörlerin Cronbach Alfa değerlerinin 0,45-0,79 arasında ve genel içsel tutarlılık katsayısının ise 0,72 olmasından araştırmada kullanılan anketin oldukça güvenilir olduğu anlaşılmıştır.

\section{BULGULAR}

Tablo 1'de araştırmaya katılan sağlık personelinin sosyo-demografik özellikleri olarak yaş, cinsiyet, pozisyon, meslekte çalışma süresi, haftalık çalışma saati ve çalıştığı birime yer verilmiş ve değerlendirilmiştir.

Tablo 1. Araştırma Kapsamındaki Sağlık Personelinin Sosyo-Demografik Özellikleri

\begin{tabular}{lccc}
\hline \multicolumn{2}{c}{ Sosyo-Demografik Bilgiler } & $\mathrm{N}$ & $\%$ \\
\hline \multirow{4}{*}{ Yaş } & 30 ve altı & 57 & 75,0 \\
& $31-40$ & 17 & 22,3 \\
& 41 ve üstü & 2 & 2,7 \\
Cinsiyet & Toplam & 76 & 100 \\
& Kadın & 60 & 79 \\
& Erkek & 16 & 21 \\
& Toplam & 76 & 100 \\
\hline \multirow{3}{*}{ Pozisyon (Görev Tanımı) } & Doktor & 9 & 11,8 \\
& Hemşire & 64 & 84,2 \\
& Diğer & 3 & 4 \\
Meslekte Çalışma Süresi (Yıl) & Toplam & 76 & 100 \\
& 5 ve altı & 64 & 84,2 \\
& $6-10$ & 11 & 14,5 \\
Haftalık Çalışma Saati & 11 ve üstü & 1 & 1,3 \\
& Toplam & 76 & 100 \\
\hline \multirow{4}{*}{ Çalıştığı Birim } & 40 ve altı & 5 & 6,6 \\
& $41-59$ & 44 & 57,9 \\
& 60 ve üstü & 27 & 35,5 \\
& Toplam & 76 & 100 \\
\hline
\end{tabular}

Tablo 1 incelendiğinde, araştırmaya katılan 76 sağlık personelinin dörtte üçünün (\% 75) 30 ve altı yaş grubunda olduğu, buna bağlı olarak da mesleğe yeni başlayanların sayısının fazla olduğunu söyleyebiliriz. Zaten meslekte çalışma süresine göre katılımcıları incelediğimizde, 5 ve altı yıl süre ile çalışanlar grubunun \% 84,2 olduğu görülmektedir. Katılımcıların \% 50,4'ünün hemşirelerden oluştuğu araştırmada, cinsiyete göre karşılaştırma yaptığımızda hemşirelerin büyük çoğunluğunun bayan olmasından dolayı doğal olarak araştırmanın yarıdan fazlasının, yani \% 84,2'sinin kadınlardan oluştuğu görülmektedir. Dâhili birimler ile cerrahi birimlerde çalışan personel sayısının tüm çalışanların yarısını oluşturduğu araştırmada, haftalık çalışma saati açısından ise katılımcıların yaklaşık yarısının 41-59 saat arası çalıştığı görülmektedir. 
Tablo 2. Sağlık Personelinin Hasta Güvenliği Kültürü Boyutlarına İlişkin Algılarının Genel Dağılımı (n=76)

\begin{tabular}{lcc}
\hline Hasta Güvenliği Kültürü Boyutları & Ortalama & $\begin{array}{c}\text { Standart } \\
\text { Sapma }\end{array}$ \\
\hline 1. Birimler içinde ekip çalışması & 3,28 & 0,79 \\
2.Yönetici beklentileri ve hasta güvenliğini & 3,02 & 0,59 \\
geliştirme faaliyetleri & 3,24 & 0,66 \\
3. Örgütsel öğrenme ve sürekli iyileştirme & 2,63 & 0,55 \\
4. Hasta güvenliği için hastane yönetiminin desteği & 2,72 & 0,38 \\
5. Güvenliğin kapsamlı algılanması & 3,12 & 0,65 \\
6. Hatalar hakkında iletişim ve geribildirim & 2,78 & 0,51 \\
7. İletişimin açık tutulması & 2,76 & 0,87 \\
8. Hataların raporlanma sıklığı & 2,98 & 0,58 \\
9. Hastane birimleri arasında ekip çalışması & 2,43 & 0,85 \\
10. Personel sağlama & 2,32 & 0,54 \\
11. Hastanede devirler ve nakiller & 3,10 & 0,74 \\
12. Hataya karş1 cezalandırıcı olmayan yanıt & 2,87 & \\
\multicolumn{1}{c}{ Genel Ortalama } & & \\
\hline
\end{tabular}

Tablo 2'de sağlık personelinin Hasta Güvenliği Kültürü Anketinde 42 ifadeden oluşan 12 boyuta ne düzeyde katıldıklarını gösteren ortalama puanlar yer almaktadır. Tablo 2'de yer alan boyutların değerlendirilmesinde araştırma sonuçlarına ortalamalar açısından bakıldığında "birimler içinde ekip çalışması" boyutunun 3,28 $\pm 0,79$ ortalama ile en

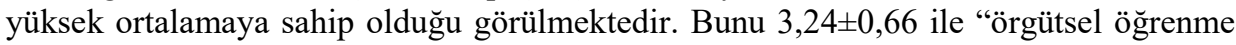
ve sürekli iyileştirme", 3,12 $\pm 0,65$ ile "hatalar hakkında iletişim ve geribildirim" ve $3,10 \pm 0,74$ ile de "hataya karşı cezalandırıcı olmayan yanıt" boyutları takip etmektedir. $2,32 \pm 0,54$ ortalama ile "hastanede devirler ve nakiller" boyutunun en düşük ortalamaya

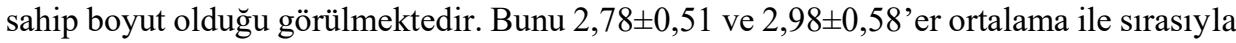
"iletişimin açık tutulması" ve "hastane birimleri arasında ekip çalışması" boyutları ve $3,02 \pm 0,59$ ile de "yönetici beklentileri ve hasta güvenliğini geliştirme faaliyetleri” takip etmektedir. En düşük boyutlar, personel algısının düşük olduğu ve geliştirilmesi ya da iyileştirme yapılması gereken alanlardır.

Tablo 3. Kruskal Wallis Testi Sonuçları

\begin{tabular}{lcccccc}
\hline \multicolumn{1}{c}{ Hasta Güvenliği Kültürü Boyutları } & $\begin{array}{c}\text { Meslekte } \\
\text { Çalışma } \\
\text { Süresi }\end{array}$ & $\mathrm{n}$ & $\begin{array}{c}\text { Sıra } \\
\text { Ortalamas }\end{array}$ & $\mathrm{Sd}$ & $\mathrm{x}^{2}$ & $\mathrm{p}$ \\
\hline \multirow{2}{*}{ 1. Birimler içinde ekip çalışması } & $\begin{array}{c}5 \text { ve altı } \\
6-10\end{array}$ & $\begin{array}{c}11 \\
11\end{array}$ & $\begin{array}{c}59,67 \\
66,42\end{array}$ & 2 & 8,511 & 0,14 \\
& 11 ve üstü & 1 & 38,53 & & & \\
\hline 2.Yönetici beklentileri ve güvenlik & 5 ve altı & 64 & 56,11 & & & \\
geliştirme faaliyetleri & $6-10$ & 11 & 60,11 & 2 & 0,228 & 0,892 \\
\hline 3. Örgütsel öğrenme ve sürekli & 11 ve üstü & 1 & 57,55 & & & \\
geliştirme & 5 ve altı & 64 & 49,75 & & & \\
& $6-10$ & 11 & 82,89 & 2 & 16,039 & 0,000 \\
4. Hasta güvenliği için hastane & 11 ve üstü & 1 & 60,88 & & & \\
yönetiminin desteği & 5 ve altı & 64 & 58,23 & & & \\
& $6-10$ & 11 & 46,56 & 2 & 2,493 & 0,288 \\
\hline
\end{tabular}




\begin{tabular}{|c|c|c|c|c|c|c|}
\hline \multirow{3}{*}{ 5. Güvenliğin kapsamlı algılanmas1 } & 5 ve alt1 & 64 & 47,57 & \multirow{3}{*}{2} & \multirow{3}{*}{29,372} & \multirow{3}{*}{0,000} \\
\hline & $6-10$ & 11 & 58,25 & & & \\
\hline & 11 ve üstü & 1 & 91,25 & & & \\
\hline \multirow{3}{*}{$\begin{array}{l}\text { 6. Hatalar hakkında geribildirim ve } \\
\text { iletişim }\end{array}$} & 5 ve alt1 & 64 & 57,98 & \multirow{3}{*}{2} & \multirow{3}{*}{3,422} & \multirow{3}{*}{0,181} \\
\hline & $6-10$ & 11 & 45,31 & & & \\
\hline & 11 ve üstü & 1 & 63,85 & & & \\
\hline \multirow{3}{*}{ 7. İletişimin açık tutulması } & 5 ve alt1 & 64 & 55,55 & \multirow{3}{*}{2} & \multirow{3}{*}{0,501} & \multirow{3}{*}{0,778} \\
\hline & $6-10$ & 11 & 61,06 & & & \\
\hline & 11 ve üstü & 1 & 58,78 & & & \\
\hline \multirow{3}{*}{ 8. Hataların raporlanma sıklığ } & 5 ve alt1 & 64 & 61,91 & \multirow{3}{*}{2} & \multirow{3}{*}{9,893} & \multirow{3}{*}{0,007} \\
\hline & $6-10$ & 11 & 59,42 & & & \\
\hline & 11 ve üstü & 1 & 36,43 & & & \\
\hline \multirow{3}{*}{$\begin{array}{l}\text { 9. Hastane üniteleri arasında ekip } \\
\text { çalışması }\end{array}$} & 5 ve alt1 & 64 & 65,67 & \multirow{3}{*}{2} & \multirow{3}{*}{19,783} & \multirow{3}{*}{0,000} \\
\hline & $6-10$ & 11 & 50,28 & & & \\
\hline & 11 ve üstü & 1 & 30,55 & & & \\
\hline \multirow{3}{*}{ 10. Personel Sağlama } & 5 ve alt1 & 64 & 51,95 & \multirow{3}{*}{2} & \multirow{3}{*}{12,450} & \multirow{3}{*}{0,002} \\
\hline & $6-10$ & 11 & 81,58 & & & \\
\hline & 11 ve üstü & 1 & 53,83 & & & \\
\hline \multirow{3}{*}{ 11. Hastanede Devirler ve Nakiller } & 5 ve alt1 & 64 & 52,13 & \multirow{3}{*}{2} & \multirow{3}{*}{5,204} & \multirow{3}{*}{0,074} \\
\hline & $6-10$ & 11 & 64,47 & & & \\
\hline & 11 ve üstü & 1 & 68,55 & & & \\
\hline \multirow{3}{*}{$\begin{array}{l}\text { 12. Hataya Karşı Cezalandırıcı } \\
\text { Olmayan Yanıt }\end{array}$} & 5 ve alt1 & 64 & 51,83 & \multirow{3}{*}{2} & \multirow{3}{*}{5,828} & \multirow{3}{*}{0,054} \\
\hline & $6-10$ & 11 & 68,58 & & & \\
\hline & 11 ve üstü & 1 & 65,98 & & & \\
\hline
\end{tabular}

Sağlık personelinin hasta güvenliği kültürü boyutlarına ilişkin algılarının "meslekte çalışma süresi" durumuna göre dağılımı ve karşılaştırılması Tablo 3'de gösterilmiştir. Tablo 3 incelendiğinde, "örgütsel öğrenme ve sürekli geliştirme $\left(x^{2}=16,039 ; p<0,05\right)$ ", "güvenliğin kapsamlı algılanması $\left(\mathrm{x}^{2}=29,372 ; \mathrm{p}<0,05\right)$ ", "hataların raporlanma sıklığ $\left(x^{2}=9,893 ; p<0,05\right)$ ", "hastane üniteleri arasında ekip çalışması $\left(x^{2}=19,783 ; p<0,05\right)$ ", "personel sağlama $\left(\mathrm{x}^{2}=12,450 ; \mathrm{p}<0,05\right)$ " boyutlarını sağlık personelinin meslekte çalışma süresine göre karşılaştırdığımızda gruplar arasında istatistiksel olarak anlamlı bir farkın çıktığı görülmektedir. Farkın hangi gruptan kaynaklandığını tespit etmek için gruplar arasında ikili karşılaştırmalar Mann Whitney U Testi ile test edilmiş ve farkın "11 ve üstü” yıl çalışan grubundan kaynaklandığ 1 görülmüş̧ür. "11 ve üstü” y1l çalışan grubunun "güvenliğin kapsamlı algılanması" boyutu hariç, diğer boyutlardaki algısının diğer grupların algısından genellikle daha düşük olduğu görülmektedir.

Tablo 4. Sağlık Personelinin Hasta Güvenliği Derecesine İlişkin Görüşleri

\begin{tabular}{lccc}
\hline Hasta Güvenliği Derecesi & Puan & $\mathrm{n}$ & $\%$ \\
\hline Mükemmel & 5 & 4 & 5,3 \\
Çok iyi & 4 & 8 & 10,6 \\
Kabul edilebilir & 3 & 19 & 25 \\
Zayıf & 2 & 27 & 35,5 \\
Başarısız & 1 & 18 & 23,6 \\
TOPLAM & 15 & 76 & 100 \\
Hasta Güvenliği Derecesi Ortalama Puanı & \multicolumn{3}{c}{2,68} \\
\hline
\end{tabular}

Sağlık personelinin hasta güvenliğine derecesine ilişkin görüşleri Tablo 4.'de gösterilmiş ve değerlendirilmiştir. Tablo 4 incelendiğinde sağlık personelinin hastanedeki hasta 
güvenliği derecesini \% 5,3'ünün mükemmel, \% 10,6'sının çok iyi, \% 25'inin kabul edilebilir bulduğu; \% 35,5'inin zayıf, \% 23,6'sının da başarısız bulduğu görülmektedir.

Sağlık personelinin hasta güvenliği dercesine ilişkin görüşlerini iyi (Mükemmel ve Çok iyi), orta (Kabul edilebilir) ve kötü (Zayıf ve Başarısız) olarak grupladığımızda, bunun çalışılan birime göre farklılaşıp farklılaşmadığı incelenmiş ve sonuçlar Tablo 5.'de gösterilmiştir. Tablo 5. incelendiğinde, gruplar arasında istatistiksel olarak anlamlı bir farkın çıktığı görülmektedir $\left(x^{2}=10,334 ; \mathrm{p}<0,05\right)$. Dahili birimlerde çalışan sağlık personelinin hasta güvenliği derecesini, \% 21,1' inin orta ve \% 71,3' ünün de zayıf olarak algıladığı ve bu grupta çalışan sağlık personelinin algısının, cerrahi ve diğer birimler grubunda çalışan sağlık personelinin algısından daha düşük olduğu görülmektedir.

Tablo 5. Ki-Kare Test Sonuçları

\begin{tabular}{lcccccccc}
\hline \multirow{2}{*}{ Hasta Güvenliği Sonuçları Çalıştı̆̆ Birim } \\
\cline { 2 - 8 } & \multicolumn{2}{c}{ Dahili } & \multicolumn{7}{c}{ Cerrahi } & \multicolumn{2}{c}{ Diğer* } & \multirow{2}{*}{${ }^{2}$} & \multirow{2}{*}{$\mathrm{P}$} \\
\cline { 2 - 7 } & $\mathrm{n}$ & $\%$ & $\mathrm{n}$ & $\%$ & $\mathrm{n}$ & $\%$ & & \\
\hline İyi & 3 & 6,6 & 5 & 18,5 & 4 & 36,4 & & \\
Orta & 8 & 21,1 & 8 & 29,6 & 3 & 27,2 & 10,334 & 0,035 \\
Zayıf & 27 & 71,3 & 14 & 51,9 & 4 & 36,4 & & \\
TOPLAM & 38 & 100 & 27 & 100 & 11 & 100 & & \\
\hline
\end{tabular}

* Röntgen ve Laboratuar Birimi

Sağlık personelinin olay raporlama ile ilgili durumu Tablo 6'da gösterilmiş ve incelenmiştir. Tablo 6 . incelendiğinde, sağlık personelinin beşte üçünden fazlasının (\% 67,1) son bir yıl içerisinde hiç olay raporu bildiriminde bulunmadığ olay raporu bildirenlerin oranı $\% 26,3$ 'dir. 3 ve üzeri olay raporu bildirenlerin oranı ise sadece $\%$ 6,6'dir.

Tablo 6. Sağlık Personelinin Tarafından Raporlanan Olay Sayısı

\begin{tabular}{ccc}
\hline Raporlanan Olay Sayıs1 & $\mathrm{n}$ & $\%$ \\
\hline 0 & 51 & 67,1 \\
$1-2$ & 20 & 26,3 \\
3 ve üzeri & 5 & 6,6 \\
TOPLAM & 76 & 100 \\
\hline
\end{tabular}

\section{SONUÇ VE DEĞERLENDİRME}

Tablo 2'de boyutların değerlendirilmesinde araştırma sonuçlarına ortalamalar açısından bakıldığında "birimler içinde ekip çalışması" boyutunun 3,28 ortalama ile en yüksek ortalamaya sahip olduğu görülmektedir. Bunu 3,24 ile "örgütsel öğrenme ve sürekli iyileştirme" boyutu takip etmektedir. Boyutlardan 2,32 ortalama ile "hastanede devirler ve nakiller" boyutunun en düşük ortalamaya sahip boyut olduğu görülmektedir. Bunu 2,78'er ortalama ile "iletişimin açık tutulması" ve "hastane birimleri arasında ekip çalışması" boyutları ve 3,02 ile de "yönetici beklentileri ve hasta güvenliğini geliştirme faaliyetleri” boyutu takip etmektedir. Aynı anket kullanarak Ankara' da yapılan başka bir çalışmada "birimler içinde ekip çalışması" boyutu 4,06 ile en yüksek ortalamaya sahip olurken "hataların raporlanma sıklığı" ve "hataya karşı cezalandırıcı olmayan yanıt" 
boyutları en düşük ortalamaya sahip boyutlar olmuştur (Teleş, 2011: 90). Yine aynı anketi kullanarak Konya'da üç farklı hastanede yapılan başka bir çalışmada, "hastane birimleri arasında ekip çalışması" boyutu \% 63 puanla en yüksek olumlu cevap yüzdesinde sahip olurken, "hataların raporlanma sıklığı" boyutu \% 15, "hataya karşı cezalandırıcı olmayan yanıt" boyutu \% 19 puanla en düşük iki boyutu oluşturmuştur (Filiz, 2009: 53). Hollanda, Tayvan ve Amerika'da birçok hastanede uygulanan hasta güvenliği kültürü anketinin sonuçlarının ortalaması alınarak ülkeler arası bir karşılaştırmanın yapıldığı bir araştırmada "birimler içinde ekip çalışması" boyutu, Hollanda'da 45 hastanenin ortalamas1 \% 85, Tayvan'da 74 hastanenin ortalamas1 \% 81, Amerika'da 622 hastanenin ortalaması \% 79 olan en yüksek ortalamayı oluşturan boyut olmuştur. "Hastane birimleri arasında ekip çalışması" boyutu \% 28 ile Hollanda'da en düşük boyut olurken, "Hataya karşı cezalandırıcı olmayan yanıt" \% 31 ile Tayvan'da ve \% 44 ile de Amerika'da en düşük boyut olmuştur (Wagner vd., 2013: 216). Bu çalışmada ve diğer birçok hem ulusal hem de uluslararası çalışmada görüldüğü gibi "birimler içinde ekip çalışması" boyutunun en yüksek ortalamaya sahip boyut olduğu görülmektedir. En düşük boyutlar ise ülkeden ülkeye değişebildiği gibi, hastaneden hastaneye de değişebilmektedir.

Çalışmada, boyutlardan "hastanede devirler ve nakiller" boyutunun en düşük boyut olması bu hastanede hastaların başka birimlere naklinde ya da nöbet değişikliği sırasında önemli problemlerin yaşandığını göstermektedir. "İletişimin açık tutulması" boyutunun düşük çıkması, çalışanların bir hata olduğunda fikirlerini özgürce ifade edemediklerini göstermektedir. "Hastanede birimler arası ekip çalışması" boyutunun düşük çıkması, birimler arası işbirliği yapma ve birlikte çalışma durumlarında problemler yaşandığını göstermektedir. "Yönetici beklentileri ve hasta güvenliğini geliştirme faaliyetleri" boyutunun düşük çıkması, hastane yönetiminin hasta güvenliği kültürünün geliştirilmesine yönelik çalışmalarının yetersiz olduğuna işaret etmektedir.

Sağlık personelinin hasta güvenliği kültürü boyutlarına ilişkin algılarının meslekte çalışma süresine göre karşılaştırılması incelendiğinde, 11 ve üstü yıl çalışanlar grubunun algısının genellikle daha düşük olduğu görülmektedir. Çalışma süresi artıkça, sağlık personelinin hastanede yapılan hatalarla karşılaşma sıklığı daha fazla olacağından 11 ve üstü yıl çalışanlar grubunun algısı daha düşük çıkmış olabilir. Tablo 4'e bakıldığında sağlık personelinin \% 15,9'u hasta güvenliği derecesini mükemmel ya da çok iyi olarak değerlendirirken, \% 25'i kabul edilebilir, yarısından fazlası da $(\% 59,1)$ zayıf ya da başarısız olarak değerlendirmiştir. Teleş (2011)'in yapmış olduğu çalışmada hasta güvenliği derecesini sağlık personelinin \% 33,9'unun mükemmel ve çok iyi, \% 47,6'sının kabul edilebilir, \% 18,5'nin de zayıf ya da başarısız bulduğu görülmektedir. Özetle yapılan çalışmalar karşılaştırıldığında en düşük hasta güvenliği derecesi çalışmamızda görülmektedir.

Araştırmada hastanenin hasta güvenliği derecesi ortalama puanı 2,68 çıkmıştır. Bu değer kabul edilebilir olan 3 puan seçeneğinin altındadır. Teleş (2011)'in yapmış olduğu çalışmada bu puan 3,17 çıkmıştır. Çakır, (2007)'ın İzmir'de yaptığı başka bir çalışmada hasta güvenliği derecesi ISO 9001:2000 belgesine sahip hastanelerde 3,92 ile çok iyi ve kabul edilebilir arasında bir değer çıkarken, bu belgeye sahip olmayan hastanelerde 2,75 ile kabul edilebilir ve zayıf arasında çıkmıştır. Araştırmada, hasta güvenliği derecesinin çok iyi ya da mükemmel olarak algılanmaması, burada iyileştirmelerin yapılması gerektiğini göstermektedir. 
Çalışmada ayrıca, dâhili birimlerde çalışan sağlık personelinin hasta güvenliği derecesi algısının daha düşük olduğu ve sağlık personelinin nerdeyse beşte üçünün son bir yıl içerisinde hiç olay raporu bildiriminde bulunmadığı görülmüştür. Son bir yıl içerisinde hiç olay raporu doldurmayanların oranı Teleş (2011)'in çalışmasında \% 69,8, Filiz (2009)'in çalışmasında \% 84,4, Çakır (2007)'ın çalışmasında ise \%81,5 çıkmıştır. Hem bu çalışmada hem de diğer çalışmalarda olay raporu doldurma oranının çok düşük olması, personelin raporlamaya teşvik edilmesi için gerekli önlemlerin alınması gerektiğine işaret etmektedir.

Boyutlardan "hastanede devirler ve nakiller, iletişimin açık tutulması, hastanede birimler arası ekip çalışması, yönetici beklentileri ve hasta güvenliğini geliştirme faaliyetleri" boyutlarının düşük çıkması, hastane yönetiminin hasta güvenliği kültürünün geliştirmede öncelik vermesi gereken alanları göstermektedir. Sağlık personelinin sadece yarısının hasta güvenliği derecesini çok iyi ya da mükemmel olarak değerlendirilmesi ve ortalama hasta güvenliği derecesinin 2,68 çıkması, bu alanda iyileştirme firsatlarının olduğunu göstermektedir. Sağlık personelinin olay raporu doldurma oranının çok düşük olduğu hastanede, sağlik personelinin olay raporu doldurmaya teşvik edilmesi ve kurum içerisinde olay raporu doldurma oranının artması için gerekli eğitimlerin verilmesi sağlanmalıdır.

\section{KAYNAKÇA}

Akalın, H. E. (2004). Hasta Güvenliği Kültürü: Nasıl Geliştirebiliriz. Ankem Dergisi, 18(2), 12-13.

Akalın, H. E. (2010). Hasta Güvenliği Kültürü. Sağllkta Nabız, 7(25), 10-13.

Akalın, H. E. (2014). Hasta Güvenliği: Değişen Paradigma. Sağlık Düşüncesi ve Tıp Kültürü Dergisi, 32, 64-67.

Alpar, R. (2010). Spor, Săglık ve Ĕ̆itim Bilimlerinden Örneklerle Uygulamalı İstatistik ve Geçerlik-Güvenirlik. Ankara: Detay Yayıncılık.

Altındiş, M. (2014). Hasta Güvenliği ve Komplikasyonlar. Sağlık Düşüncesi ve Tıp Kültürü Dergisi, 32, 68-73.

Budak, M. (2008). Hasta Güvenliği Kültürü. Sağlık Düşüncesi ve Tıp Kültürü Dergisi, 7, 54-57.

Çakır, A. (2007). Hasta Güvenliği Kültürü ile Kalite Yönetim Sistemi Arasındaki İlişkinin Analizi. Yayınlanmamış Yüksek Lisans Tezi. İzmir: Dokuz Eylül Üniversitesi.

Çakmakçı, M. (2014). Hasta Güvenliği: Bir Paradigma Değişimi. Sağllk Düşüncesi ve Tıp Kültürü Dergisi, 33, 6-11.

Deilkas, E. T., \& Hofoss, D. (2008). Psychometric properties of the Norwegian version of the Safety Attitudes Questionnaire (SAQ), Generic version (Short Form 2006). BBMC Health Services Research, 8(191), 1-10. doi:10.1186/1472-6963-8-191 
Filiz, E. (2009). Hastanede Hasta Güvenliği Kültürü Algılamasının ve Sağlık Çalışanları ile Toplumun Hasta Güvenliği Hakkındaki Tutumunun Belirlenmesi. Yayınlanmamış Yüksek Lisans Tezi. Konya: Selçuk Üniversitesi.

Gözlü, K. \& Kaya, S. (2012). Akreditasyon Belgesine Sahip Bir Hastanede Hasta Güvenliği Kültürünün Değerlendirilmesi. 6. Ulusal Sağlık ve Hastane İdaresi Kongresi, Isparta, ss.175-182.

Güven, R. (2007). Dezenfeksiyon ve Sterilizasyon Uygulamalarında Hasta Güvenliği Kavrami. 5. Ulusal Sterilizasyon Dezenfeksiyon Kongresi, 4-8 Nisan, Antalya, ss. 411-422.

Institute of Medicine, (2000), To Err is Human: Building a Safer System. Washington DC.: National Academiy Press.

Institute of Medicine, (2003), Priority Areas For National Action: Transforming Health Care Quality. Washington DC.: National Academiy Press.

Kaya, S. (2007). Türkiye'deki Hastanelerde Hasta Güvenliği Kültürü. Uluslararası Sağlık ve Hastane Yönetimi Kongresi, KKTC Yakın Doğu Üniversitesi Eğitim Vakfı, KKTC: Devlet Basımevi.

Kaya, S. (2009). Hasta Güvenliği Kültürü Nedir ve Nasıl Geliştirilebilir?. Sağllk Hizmetlerinde Kalite, Akreditasyon ve Hasta Güvenliği Dergisi, 1(1), 32-34.

Kohn, L.T., Corrigan, J.M., Donaldson, M.S., McKay, T. \& Pike, K.C. (2000). To Err is Human: Building a Safer System. Washington, DC: National Academy Press.

Naveh, E., Katz-Navon, T., \& Stern, Z. (2005). Treatment Errors in Healthcare: A Safety Climate Approach. Management Science, 51(6), 948-960. doi: $10.1287 / \mathrm{mnsc} .1050 .0372$

Saraç, A. (2009). Trabzon İl Merkezinde Birinci Basamakta Çalışan Sağllk Personelinin Hasta Haklarl, Hasta Güvenliği ve Kendi Hakları Hakkındaki Bilgi ve Tutumlarl. Yayınlanmamış Yüksek Lisans Tezi. Trabzon: Karadeniz Teknik Üniversitesi.

Sorra, J. S., \& Dyer, N. (2010). Multilevel Psychometric Properties of the AHRQ Hospital Survey on Patient Safety Culture. BMC Health Services Research, 10(199), 1-13. doi: 10.1186/1472-6963-10-199

Tak, B. (2010). Sağlık Hizmetlerinde Kalitenin Ana Unsuru Olarak Hasta Güvenliği Sistemlerinin Oluşturulması: Hastaneler İçin Bir Yol Haritası Önerisi. Sağllkta Kalite ve Performans Dergisi, 1,72-113.

Teleş, M. (2011). Sağlık Personelinin Hasta Güvenliği Kültürü Alglları Ile Hastaların Sağlık Hizmeti Kalitesi Algıları Arasındaki İlişkinin Analizi. Yayınlanmamış Yüksek Lisans Tezi. Ankara: Hacettepe Üniversitesi.

Wagner, C., Smits, M., Sorra, J., \& Huang, C. C. (2013). Assessing Patient Safety Culture in Hospitals Across Countries. International Journal for Quality in Health Care, 25(3), 213-221. doi: 10.1093/intqhe/mzt024 